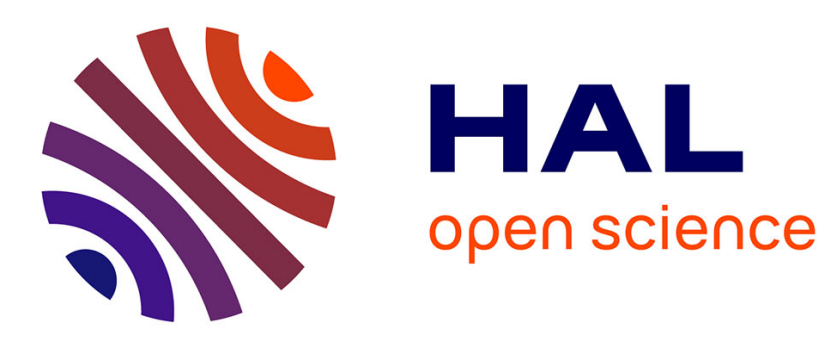

\title{
Truth in the Digital Library: From Ontological to Hermeneutical Systems
}

\author{
Aurélien Bénel, Elod Egyed-Zsigmond, Yannick Prié, Sylvie Calabretto, Alain \\ Mille, Andrea Iacovella, Jean-Marie Pinon
}

\section{- To cite this version:}

Aurélien Bénel, Elod Egyed-Zsigmond, Yannick Prié, Sylvie Calabretto, Alain Mille, et al.. Truth in the Digital Library: From Ontological to Hermeneutical Systems. ECDL 2001: Research and Advanced Technology for Digital Libraries, 2163, Springer, pp.366-377, 2001, Lecture Notes in Computer Science, 10.1007/3-540-44796-2_31. hal-02363487

\section{HAL Id: hal-02363487 \\ https://hal-utt.archives-ouvertes.fr/hal-02363487}

Submitted on 12 Jun 2021

HAL is a multi-disciplinary open access archive for the deposit and dissemination of scientific research documents, whether they are published or not. The documents may come from teaching and research institutions in France or abroad, or from public or private research centers.
L'archive ouverte pluridisciplinaire HAL, est destinée au dépôt et à la diffusion de documents scientifiques de niveau recherche, publiés ou non, émanant des établissements d'enseignement et de recherche français ou étrangers, des laboratoires publics ou privés. 


\title{
Truth in the Digital Library: From Ontological to Hermeneutical Systems*
}

\author{
Aurélien Bénel $^{\dagger \dagger}$, Elöd Egyed-Zsigmond ${ }^{\dagger \S}$, Yannick Prié ${ }^{\S}$, Sylvie Calabretto ${ }^{\dagger}$, \\ Alain Mille $^{\S}$, Andréa Iacovella ${ }^{\ddagger}$, Jean-Marie Pinon ${ }^{\dagger}$ \\ $(\dagger)$ LISI - INSA Lyon \\ Bâtiment Blaise Pascal, 69621 Villeurbanne CEDEX, France \\ Firstname.Surname@lisi.insa-lyon.fr \\ ( ) French School of Archaeology (EFA) \\ 6 Didotou street, 10680 Athens, Greece \\ Firstname.Surname@efa.gr \\ (§) LISI - Université Lyon 1 \\ Bâtiment Nautibus, 69622 Villeurbanne CEDEX, France \\ \{eegyed, yprie, amille\}@lisi.univ-lyonl.fr
}

\begin{abstract}
This paper deals with the conceptual structures which describe document contents in a digital library. Indeed, the underlying question is about the truth of a description: obvious (ontological), by convention (normative) or based on interpretation (hermeneutical). In the first part, we examine the differences between these three points of view and choose the hermeneutical one. Then in the second and third part, we present two "assisted interpretation systems" (AIS) for digital libraries (audiovisual documents and scholarly publications). Both provide a dynamic annotation framework for readers' augmentations and social interactions. In the fourth part, a few synthetic guidelines are given to design such "assisted interpretation systems" in other digital libraries.
\end{abstract}

Keywords. Interpretation, collaboration, annotation, ontology, graphs, interactive information retrieval, assisted interpretation systems.

\section{Introduction}

How can we solve in digital libraries the problems of structuring, interoperability and reuse? The current approach is to consider Ontology, a concept borrowed from philosophy, as the panacea. This borrowing seems so legitimate that researchers have only discussed related topics like cost [17]. But there are other metaphysics of Truth (Conventionalism and especially Hermeneutics) that could be more useful to the creators and users of digital libraries.

\footnotetext{
${ }^{*}$ The authors are truly indebted to Phyllis Graham for her help with the English manuscript.
} 
One can argue that Ontology and its metaphysical aspects are not to be confused with the ontologies which are proposed by computer scientists. But, as we will see, the simple use of the term "ontology" implies the admission of its a priori understanding of reality.

In the first part, we will discuss the postulates and consequences of the ontological approach and introduce the conventional and hermeneutical ones. We firmly support the hermeneutical approach (i.e. based on interpretation) and its interactive and collaborative aspects. In the next two parts, we will present two assisted interpretation systems (AIS) for digital libraries: E-SIA and Porphyry 2000. In the last part, we will propose some general criteria for building hermeneutical digital library systems.

\section{Ontology and hermeneutics}

The particular concern of computer science in "ontologies" comes from its original relationship to reality. On the one hand, computer science derives from modern mathematics which are based on conventionalism. In this approach, there is no concern with the conformity to the real world. Only the internal coherence of a conventionally true ("axiomatic") system matters. On the other hand, computer science as a support for human practices is an applied science and should keep a connection between its formal results and the "real world".

The ontological approach dates from Aristotle [2]. By definition, it is the metaphysical study of being or, more pragmatically, the a priori structure of reality. It is based on the utterance of obviously true principles ("true" means "complying with reality"). This way, every deduced proposition complies with reality. Much discussions has concerned Ontology, but nobody has yet managed to get it. We know several "local ontologies". However they are often mutually contradictory and hard to reuse in different applications [6]. There are also many great philosophers, logicians and computer scientists who have tried to find the "top-level ontology" [11]: starting from Aristotle's categories, to Ontolingua [13], and passing through Pierce's categories. But we can't help questioning the ontological approach itself when we read the lengthy catalogue [16] of these works.

The "apriorism" of the ontological approach does not correspond to the practice of those who take part in the consensual elaboration of thesauri or domain models. And in fact, the "ontology" concept, in its postmodern meaning, is a mix of a priori truth, conventional truth and consensual truth. It is often referred as a "common ground" for communication within a group [18] or as capturing consensual knowledge as accepted by a group [13] [6]. Indeed experts know that constructing a model is a slow, difficult, collective and regularly repeated process. Even in well defined and formalized domains (medicine, zoology), experts seldom agree on well established concepts [17]. As a matter of fact, the knowledge modeler has had to abandon the ontological "apriorism" in order to continue working. "Apriorism" did not provide many guidelines on how to handle models through their creation, evolution, shared use, learning by a human, fusion, and dependence on practices.

On the contrary, these aspects of collaborative construction are well represented in the hermeneutic approach. Traditionally, hermeneutics deals with the production and 
interpretation of text and speech. "Interpretation" is used in the sense of a "trail" [23] in a text or a system of signs. This requires an interpreted subject situated in an action, a social practice, a history and a culture.

Whereas the ontological approach stresses representation, the hermeneutic one gives priority to communication. While, for the former, properties of an occurrence are inferred from relations between types, for the latter there are only source occurrences and revisited occurrences influencing each other. In addition, the first approach assumes a knowledge "revelation" while the second proposes a hypothetical, transitory, and debate-based knowledge construction.

In a few words, two communicating people must adapt their own vision of the world, learn from each other, discover the other's subjectivity, understand the other's interpretations, and resolve misunderstandings. In the next sections we will illustrate this theoretical approach with two systems we have designed.

\section{Illustration \#1 : E-SIA}

\section{Context and motivation}

The E-SIA (Extended Annotation Interconnected Strata) model is developed in a project supervised by the French National Telecommunication Research Network (RNRT), in collaboration with France Télécom ${ }^{1}$ and INRIA ${ }^{2}$.

The objective of this project is to study and develop tools that enrich access and research services to multimedia information.

Our team focuses mainly on document description. In fact both the search and the annotation pass through a description process. In the first case we describe what we would like to find, in the second the description concerns what we perceive and interpret. In our case the description is done by annotating the documents. As the description is done by different users in different circumstances, it is important to provide tools making possible a homogeneous annotation. For example in the case of a sport TV program it is annoying if the participants of a cycle race are designated at different times as runners, cyclists, or competitors.

Annotation is controlled by a vocabulary. This means that every term used to annotate has to be added to a sort of thesaurus. Once a term is in the vocabulary it can be reused to annotate documents. We have developed a document description model, to organize and exploit annotations. For the moment, this model concerns audiovisual documents and provides thesaurus management, query construction and refinement of queries. We have created a prototype application enabling document annotation and exploitation [10], managing these annotations as XML documents.

In our system both the documents and the annotations are distributed over a network. We want to make it possible for users to exploit and over-annotate the descriptions created by others. It is in the collaborative use of the vocabulary that one

\footnotetext{
${ }^{1}$ France Telecom Recherche et Développement (http://www.rd.francetelecom.fr/)

${ }^{2}$ Institut National de Recherche en Informatique et Automatique (http://www-rocq.inria.fr/imedia/)
} 
of the major difficulties of the project resides. Several persons (with different cultural and professional backgrounds) modify the vocabulary annotating and over-annotating documents ("using knowledge changes knowledge" [17]). We insist on the fact that annotations are freely added by individual users, but can be controlled (in the case of institutions, like TV channels archiving their programs according to precise guidelines). As these guidelines are documented their interpretation and comprehension should be easy.

\section{System Overview}

The E-SIA system relays on a graph based document description model [22]. The annotations and the documents are distributed, the system is used by a large number of users.

In E-SIA, documents are described by annotations (AE) taken from a "knowledge base" defining the vocabulary (abstract annotation elements (AAE)) to be used for annotation. These terms can be grouped in analysis dimensions (AD). This way, they form smaller sets useful for a given annotation task. The annotation elements (AE) describe document fragments represented in the graph by audiovisual units (AVU). All these elements make up a connected, labeled graph.

We propose also the formalization of annotation results. This is done by a structure called description scheme (DS). It specifies which analysis dimensions (AD) are to be used, and which relations are to be created between the descriptors. We say that the annotation is done following a DS. Relations defined in description schemes and instanced across annotation elements, define contexts between these AE-s. Elements are contextualized by other elements with which they have explicit or temporal relations. For example in Fig. 1 AE:Lt.Tonton is in the context of AE:Freeing, because there is an direct relation between them. Generally, we consider any subgraph as a context.

Fig. 1 illustrates the layers composing the annotation graph. Some terms of the thesaurus are structured in 3 analysis dimensions, in order to annotate videos presenting first aid techniques in accidents. The description scheme DS:Accident specifies that a Fireman carries out Operations on Victims. We note that an other description has been done, assigning the term Fire to an audiovisual unit. This annotation was carried out following another description scheme.

A description scheme provides information on the structure of created annotations. It is possible for the same document to be described more than once, in which case we could say that it is annotated following more than one description scheme. The description schemes (SD) as well as audiovisual units (AVU), annotation elements (AE), abstract annotation elements (AAE) and analysis dimensions (AD) are nodes of the global annotation graph

In practice the annotation begins by the selection of a description scheme (it can be a very loose one). Then the user examines the document to be described and describes the user-defined parts with the AAE-s (terms) taken from the analysis dimensions of the description scheme. The user has to create the relations defined by the description scheme. 


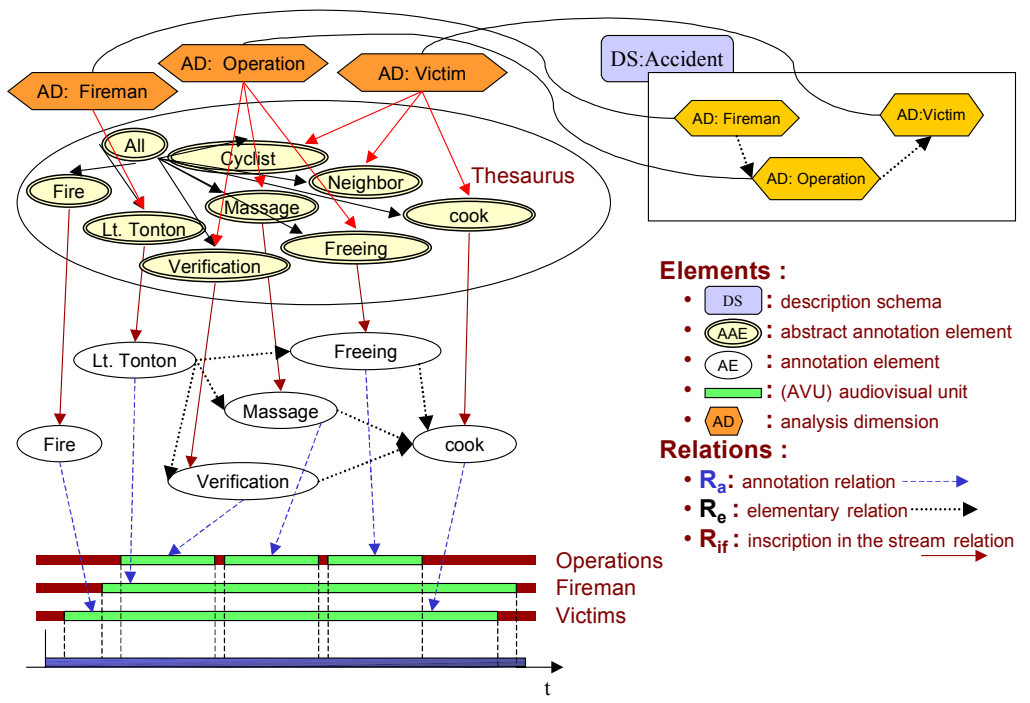

Fig. 1. The several layers composing the annotation graph in E-SIA.

After this short presentation of the E-SIA system, we concentrate now on the creation, structuring, sharing, and reuse aspects of the thesaurus.

\section{Thesaurus creation and structuring}

Even for one user, the creation and management of a structured annotation vocabulary is a difficult task. The user looks for terms he wants to use to annotate. If he doesn't find them he can create them. He groups the terms in analysis dimensions, organizes the analysis dimensions in description schemes and begins the annotation. While annotating he reiterates the thesaurus management operations. When creating a new term, some analysis dimensions may have to be updated. When a new type of document is being described for the first time, new analysis dimensions and description schemes may need to be created.

When the system is used by several users the vocabulary management becomes much more complex. In this case the diffusion of single user's structures, and their comprehension and adaptation by others is to be considered.

By grouping the terms (AAE) of the thesaurus in sets (expressed by analysis dimensions) we avoid the structuring of the vocabulary in a class hierarchy. A term can be part of several analysis dimensions. An analysis dimension is always created for a precise task, terms can be added one by one, but it can be completed by other analysis dimensions. We preserve a "trace", that is to say a record, of operations made on an analysis dimension to be able to follow its evolution.

In E-SIA it is impossible to delete an element after it has been used for annotation. This way we prevent incoherence and updating problems, every created element remains coherent with its "origins". If the user wants to restrict an analysis dimension he has to create a new one. 


\section{Thesaurus sharing and reuse}

In this section we present some tools allowing us to a priori document and constrain annotation structures and other tools which permit us to analyze existing annotations a posteriori in order to discover the methods and structures used by those who created these annotations. These tools "upstream" and "downstream" of the annotation will both serve the users in their describing and searching tasks.

As we said before, we suppose that annotation is done by different people, possibly clustered in groups. Each group has its own analysis dimensions and description schemes. In order to exploit the annotations created by a group, an external user can consult their analysis dimensions and description schemes (a priori tools) in order to build more precise queries. For the research and exploitation of annotations ( $a$ posteriori tools) we set up methods based on the navigation in the annotation graph, we created a tool based on the graph structure to represent queries and we studied statistical views (inspired by the self organizing maps of Kohonen [14]) permitting the emergence of existing annotation structures. In this way the system enables a user to exploit, understand, adapt, and reuse the annotations and structures of other users. These a posteriori tools help users and groups to improve their own structures and annotations. They allow the emergence of practical usage information making it possible to update and adapt existing description schemes and analysis dimensions. We study these tools to "warehouse" user experience for later reuse. This retention is based on the Case Based Reasoning paradigm [1].

Having these two kinds of tools (a priori and a posteriori) and using them in a loop, we enable a considerable freedom in organizing and using the annotation vocabulary and the annotation methods. At the same time we enable easy discovery and comprehension of preexisting structures and terms. We do not constrain annotation but enable the documentation of eventual description canons.

\section{Illustration \#2 : Porphyry 2000}

\section{Context and Motivation}

Our study is related to a digitization project by the French School of Archaeology in Athens $^{3}$. This project will provide online access to one of the main periodicals: "La Chronique des fouilles", an annual survey of archeological excavations and discoveries. This corpus has been chosen since although its size is reasonable (about 12,000 pages), it is nearly exhaustive in regard to the past 80 years of archaeological activity in Greece and Cyprus. In addition, the "Chronique" is read daily in libraries throughout the world.

We must stress that the information retrieval problem is not new concerning the "Chronique". Publishers have tried for 80 years to make it easier to consult. It is

\footnotetext{
${ }^{3}$ Ecole française d'Athènes (http://www.efa.gr)
} 
comprised of small independent parts (about 50,000) which are hierarchically structured and indexed according to artifact location, dating and typology.

Archaeologists who have tried retrieval systems based on automatic indexing or manual indexing using thesauri have found neither satisfactory. The former is considered inadequate because it deals with out-of-context terms. The latter is hard to manage over time by the indexing team since it needs periodic updates of both thesauri and indexes in order to reflect scientific progress.

As an example, there was several years ago a disagreement between two archaeologists about whether mosaic borders with the meander design was black or white (often ambiguous). An automatic indexing system would have extracted only the point of view in the text. Moreover, without knowing whose point of view it is, the index could not have been interpreted. As a second example, when the Copper Age was inserted in the chronology between the Neolithic Period and the Bronze Age, the thesaurus-based systems required that many documents be reinterpreted and reindexed.

\section{System overview}

Porphyry 2000 is a client-server system designed to create, retrieve, and share documents and annotations (see Fig. 2). The annotation structure is an acyclic graph of descriptors, which formally signifies that if, for two descriptors $D_{1}$ and $D_{2}, D_{1} \rightarrow D_{2}$, then any document described by $\mathrm{D}_{2}$ is described by $\mathrm{D}_{1}$ too. It is worth mentioning that only edges and nodes have significance for the system. But, so that users can interpret the graph, we store labels too. Node labels contain short descriptions and edge labels contain information (see the edge popup label in Fig. 2 at the center) about their creation (user, date) and publication (group, date). As long as the formal signification of this framework is observed, users are free to use it in order to represent: specialization, composition, attributes, attribute values, relations, etc (see Fig. 3).

Formally, the annotation structure looks like what is misleadingly called an "ontology". But, as we will see in the next three parts, its use is radically different. And this is sufficient partially to solve problems concerning creation, evolution, fusion, diffusion, and learning of this structure.

\section{Model creation and evolution}

Usually, describing a document is considered a question of "metadata" chosen by authors, editors or librarians. Therefore, we have given the system the ability to reuse the indexes and title hierarchies contained in documents. However this type of information is necessary but definitely not sufficient. Indeed, even if indexing were perfectly done, this would result in impoverishment of meaning. A document is an open work (see Umberto Eco [9]). Its meaning is given not only by the author or by the indexing professional but also by the whole of its readership. 


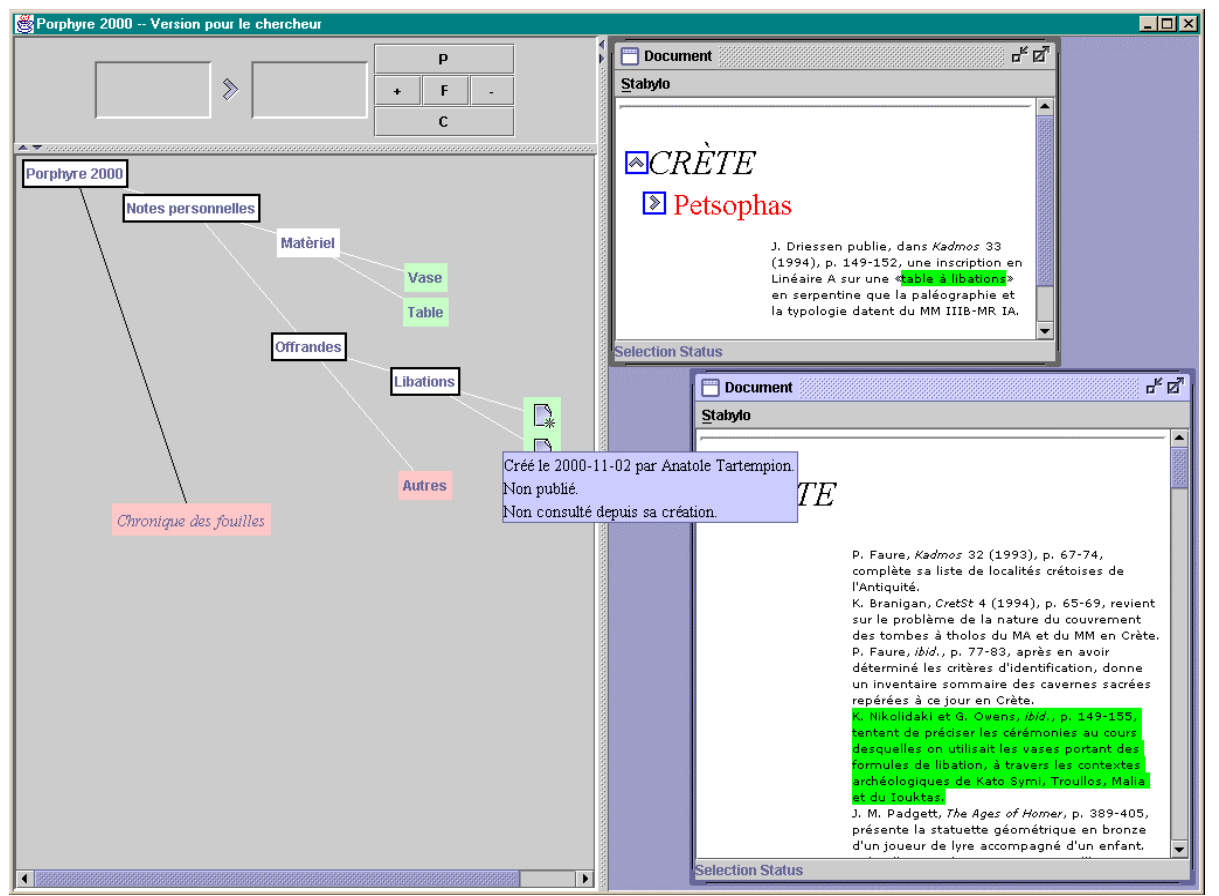

Fig. 2. Porphyry 2000 screenshot: annotations and documents.

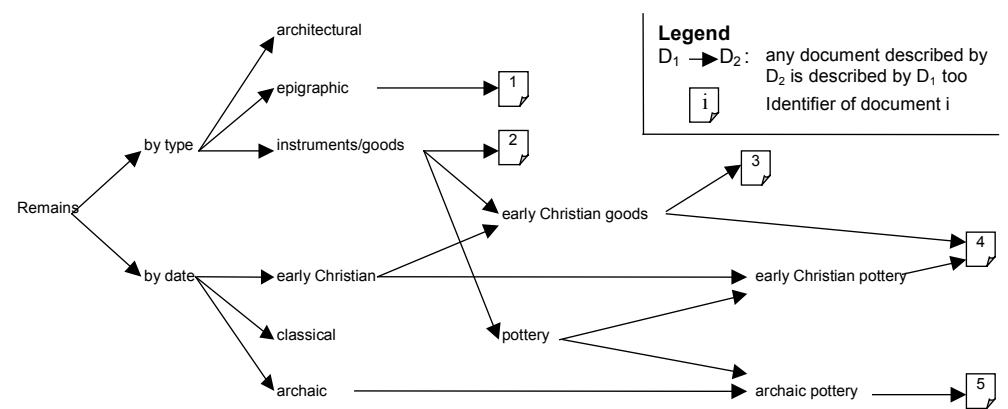

Fig. 3. Sample personal annotations.

We should note that this approach is particularly adapted to the scientists that our system is designed for. Indeed, for modern science there is no definitive knowledge but only testable theories [21]. Conformity to reality is set in a new way. The scientific tool is refutation: it is by refuting hypotheses that science progresses.

Reader augmentation in digital libraries (as in Synchrony [12]) is the subject of a recent user study by Kenton O'Hara et al. [19]. This study concerned the documentrelated research activities of Ph.D. students during a working day. It appears that their tasks go beyond the traditional searching and retrieving of information. They also take notes, photocopy, read, annotate, review information, and write documents. In short, they are not only knowledge "consumers" but also knowledge "producers". 
In our system, the metaphor used to represent user augmentations is "annotation" (as in Yawas [8]) pointing at explicit document parts (chapters, sections...) or zones highlighted by the user (see Fig. 2). Owing to the annotation structure, annotations can be collected or distinguished just as in a thematic bibliography or in the contents of an article. One of the main benefits of these personal descriptions over institutional ones is their flexibility. In fact, like draft pages, they have to "reflect" at any moment the "mind trail" of the reader.

\section{Model diffusion and fusion}

Because a library is not a document warehouse but a place for social interactions (see Klaus Tochtermann [24] and Andreas Paepcke [20]), the digital library must provide ways to share ideas. In our system, we do so by disseminating personal annotations and documents. But, given the knowledge of each individual, what is the knowledge of the group? Expressed in a different way: "How do we get a syntactic and semantic coherence from these different (and even contradictory) models?" If these questions are raised for Knowledge Managing in general, they find a traditional answer in the scientific praxis: publication.

Indeed "publication" (making public) is the key of scientific knowledge construction. Owing to pair critics (from working groups to colloquiums), scientific theories are either refuted or corroborated. In the traditional publication process, the "publishers" (real publishers, reviewers, committees...) check submitted papers regarding form and contents in order to ensure their validity for the group.

As a result we propose that in our system scientists can choose to join groups headed by "publishers" they regard as authorities. Then their annotation graph and/or documents can be "published" through the reviewing process chosen by the group.

One should note that "auto-publication" (such as a "home page" on the web) can be supported by the system as a borderline case. This is a publication in a group of limited authority, with no editorial constraints, which will have probably very few "subscribers".

Of course, the reviewing process will not resolve all the contradictions within a group. Moreover it will have little effect on the contradictions between groups. But we should emphasize that every annotation or document is situated (by its author, group, writing date, publication date). Therefore each point of view can be interpreted, and even the conflicts "make sense". The progress of science is a history of polemics within and among scientific communities (see Thomas S. Kühn [15]).

\section{Model learning \& Practice emergence}

One of the challenge of our system is to assist the researcher in learning others' theoretic models. By showing current practices, the system should help the researcher to reuse those models with which he/she agrees.

Our model consists in filtering the annotation graph during the navigation between document corpora. The principles we use are described in depth in our prior works [3][4]. In a few words, this principle can be compared with the "auto-completion" 
featured by some shells or browsers. But the structure it deals with is not hierarchical but acyclic (a "child" can have several "fathers"). Given a selection of descriptors, it consists in inducing some descriptors, in interdicting others, and in suggesting others. Therefore, from selection to selection, the user navigates through corpora until he/she finds the most pertinent one.

Owing to our system's ability to give a synthetic view of the annotation graph, we can go without thesauri. By letting practices emerge, the system can guide the user in reading (retrieval) and writing (indexing) phases. However this kind of approach, because it is inductive, could raise logicians' suspicion. In fact, it only consists in summing up (by classifying) known cases. The user is free to reuse the inducted rules for new cases or to amplify them in a theoretic model.

\section{Synthesis: Hermeneutical guidelines for Digital Libraries}

In the preceding parts, we have shown two digital library systems in which it has been possible to do away with Ontological assumptions. It is time to propose a few general guidelines to apply hermeneutics to digital libraries. We claim that, as in any complex activity, library use is composed of "methodic" tasks and "creative" ones. The former are "conventional" and can be modeled through a normative process. The latter are a "matter of discussion" and should be modeled through a hermeneutic process. To computerize such a process is quite delicate. On the one hand, if we formalize it too much, we make it "normalized". On the other hand, if we formalize it too little, we cannot provide utilities. Since we want to build an "Assisted Interpretation System", the only aspects we should fix are those concerning the hermeneutical process itself.

First, the system must deal with interpretable artifacts (called "document contents" in a broad sense) and not with signs whose signification is given. Therefore, it is a documentary system and not a factual nor a data system ("data" means "given things" in Latin). Moreover, one way for a reader to "make sense" consists in comparing various sources. As a matter of fact, documents "select" sense in each other by being read together (see Rastier). So, the system must provide the ability to compare documents (as with the "viewing positions" in the "Memex" [5]). and to gather them in perennial corpora (as in PreSS [7]). Furthermore, the system must offer not only sources but also supplementary readings provided as a basis for their critical study (apparatus criticus). In addition, the system must be able to show the source either in its original integrity or enriched with its apparatus. We should note that the apparatus can be considered as documents too and so can be interpreted and criticized.

Second, the system must store and process interpretation traces. Although interpretation trails are mental and probably unknowable, a system can capture "traces" which, once interpreted by a human, call to mind the original trails or other ones. These reading "traces" can be navigation log files, annotations, links between corpora, new documents, mediated social interactions... We must stress that in order to be interpreted the traces must be both contextualized and situated. By "context" (etymologically, "woven together") we mean the traces which are linked to one another. By "situation" we mean not only the "here and now" from linguistic pragmatics but also the persons involved, their practice and culture. 
Third, the system must provide users the ability to share their personal interpretation traces. Through the conflicts of interpretation that will arise, users can go beyond subjectivity towards intersubjectivity. Also, any assisted interpretation system should allow storage of conflicts (An interesting research direction could also be to provide utilities to assist users and groups in identifying and/or solving some of them). Last but not least, we saw that there is no constraint by default on how to describe a document. But, in order to support group practices, it is recommended that groups be able to add their own rules to the system (like DTDs in XML).

\section{Conclusion}

In this paper we have discussed the ontological and hermeneutical approach to digital libraries. Digital libraries are par excellence information universes used by many people. We have seen that there can not be a universal consensus between all these people from an ontological point of view, so other techniques must be used in order to make the system optimal. We argued that the key issue of truth in digital libraries is related to the point of view, the way people interpret terms.

In order to formulate some guidelines for "Assisted Interpretation Systems", we presented two projects related to digital libraries produced by our teams. We discussed creation, structuring, evolution, diffusion, fusion, learning, and reuse questions of thesauri and models. We reached the conclusion that AIS should be human centered, should enable the clarification of personal points of view and metaphors. It has to tolerate conflicts between humans and help them to overcome these conflicts by communication. It should be a mediation tool permitting the emergence of common practices. In practice, we argue that the system must deal with interpretable artifacts ("document contents" in a broad sense), must store interpretation traces and enable their shared use.

We plan to continue developing systems enabling the retention and reuse of collective experience. Beyond this goal, we also intend to study computer-assisted detection of conflict of interpretation.

\section{References}

[1] AAMODT A. \& PLAZA E. (1994). Case-based reasoning: Foundational issues, methodological variations, and system approaches. In Artificial Intelligence Communications. Volume 7, Issue 1. IOS Press. pp.39-59.

[2] ARISTOTLE $\left(4^{\text {th }}\right.$ century BC). Organon: Categories and Interpretation.

[3] BENEL A., CALABRETTO S., PINON J.-M. \& IACOVELLA A. (2000a). Vers un outil documentaire unifié pour les chercheurs en archéologie. In Proceedings of the $17^{\text {th }}$ Congress on Informatics and Organizations (INFORSID). In French. INFORSID Editions, Toulouse (France). pp.133-145. ISBN 2-906855-16-2.

[4] BENEL A., CALABRETTO S., PINON J.-M. \& IACOVELLA A. (2000b). Consultation de documents et sémantique : Application à des publications savantes. In Proceedings of the $2^{\text {nd }}$ International French Speaking Colloquium on Writing and Document (CIFED). In French. PPUR Editions, Lausanne (Switzerland). pp.271-280. ISBN 2-88074-460-1. 
[5] BUSH V. (1945) As we may think. In: The Atlantic Monthly. July 1945.

[6] BOUAUD J., BACHIMONT B., CHARLET J. \& ZWEIGENBAUM P. (1994). Acquisition and structuring of an ontology within conceptual graphs. In Proceedings of ICCS'94 Workshop on Knowledge Acquisition using Conceptual Graph Theory. pp.1-25.

[7] COX D. \& GREENBERG S. (2000). Supporting collaborative interpretation in distributed groupware. In Proceedings on the ACM CSCW'2000 Conference on Computer Supported Cooperative Work. pp.289-298.

[8] DENOUE L. \& VIGNOLLET L. (2000). An annotation tool for web browsers and its applications to information retrieval. In RIAO'2000 Conference Proceedings. "Contentbased multimedia information access". CID-CASIS. pp.180-195.

[9] ECO U. (1962). The Open Work. $4^{\text {th }}$ revised edition and English translation. Harvard University Publishing, 1989.

[10] EGYED-ZS. E., PRIE Y., MILLE A. \& PINON J.-M. (2000). A graph based audio-visual document annotation and browsing system. In RIAO'2000 Conference Proceedings. "Content-based multimedia information access". CID-CASIS. pp.1381-1389. ISBN 2905450-07-X

[11] GUARINO N. (1997). Some organizing principles for a unified top-level ontology. In Proceedings of AAAI 1997 Spring Symposium on Ontological Engineering. AAAI Press.

[12] GOH D. \& LEGGETT J. (2000). Patron-augmented digital libraries. In Proceedings of the Fifth ACM Conference on Digital Libraries. pp.153-163.

[13] GRUBER T.R. (1993). A translation approach to portable ontology specifications. In Knowledge Acquisition. Volume 5, Issue 2. pp.199-220.

[14] KOHONEN T. \& KASKI S. (2000). Self Organization of a Massive Document Collection. In IEEE Transactions on Neural Networks, Volume 11, Issue 3. pp.574-585

[15] KÜHN T.S. (1962). The Structure of Scientific Revolutions. University of Chicago Press.

[16] LEHMANN P. (1994). CCAT: The current status of the conceptual catalogue (Ontology) group with proposals. In Proceedings of the Fourth International Workshop on Peirce, "A conceptual Graph Workbench".

[17] MENZIES T. (1999). Cost benefits of ontologies. In ACM Magazine on Intelligence : New Visions of AI in Practice. Volume 10, Issue 3. pp.26-32.

[18] MITRA P. \& WIEDERHOLD G. (2000). A Graph-Oriented Model for Articulation of Ontology Interdependencies. Proceedings of the EDBT'2000 Conference on Extending Database Technology. Springer. 15p.

[19] O'HARA K., SMITH F., NEWMAN W. \& SELLEN A. (1998). Student readers' use of library documents: implications for library technologies. In ACM CHI'98 Conference Proceedings on Human Factors in Computing Systems. pp.233-240.

[20] PAEPCKE A. (1996). Digital libraries: Searching is not Enough. What we learned on-site. In D-Lib Magazine. May 1996.

[21] POPPER K.R. (1972). Objective Knowledge: an Evolutionary Approach. Clarendon Press.

[22] PRIE Y., MILlE A. \& PINON J.-M. (1999). A Context-Based Audiovisual Representation Model for Audiovisual Information Systems. In Context'99, Second International and Interdisciplinary Conference on Modeling and using Context, Trento (Italy). pp.296-309.

[23] RASTIER F. (1995). Le terme : entre ontologie et linguistique. In La banque des mots, $n^{\circ} 7$.

[24] TOCHTERMANN K. (1994). A first step toward communication in virtual libraries. In First Annual Conference on the Theory and Practice of Digital Libraries. College Station (Texas). June 19-21 1994. 